\title{
RANGE SHIFT OF BROMUS TOMENTELLUS BOISS. AS A REACTION TO CLIMATE CHANGE IN CENTRAL ZAGROS, IRAN
}

\author{
SANGOONY, H. ${ }^{*}$ - VAHABI, M. - TARKESH, M. - SOLTANI, S. \\ Department of Natural Resources, Isfahan University of Technology, Isfahan, 84156-83111, \\ Iran \\ *Corresponding author \\ e-mail:Hamed.Sangoony@na.iut.ac.ir,H.sangoony@gmail.com \\ (Received $3^{\text {rd }}$ May 2016; accepted $16^{\text {th }}$ Jun 2016)
}

\begin{abstract}
Climate change has been a serious matter in the last two decades and many studies focused on its different aspects. The question about the effect of a changing climate on organisms is valid for every single living soul. In this paper, we discussed the effect of climate change on geographical distribution of Bromus tomentellus Boiss. in Central Zagros, Iran. To do so, we used 19 bioclimatic variables and 8 modeling approaches (Generalized Linear Model (GLM), Surface Range Envelope (SRE), , Flexible Discriminant Analysis (FDA) Classification Tree Analysis (CTA), Artificial Neural Network (ANN), Generalized Boosting Method (GBM), Multivariate Adaptive Regression Splines (MARS) and Random Forest (RF)) to quantify the climate change in 2080 and scrutiny its effects on range shift of Bromus tomentellus. The results showed that annual precipitation (BIO12), mean temperature of wettest quarter (BIO8), mean diurnal range (BIO2) and temperature seasonality (BIO4) has the most importance for habitat suitability of this species. Bromus tomentellus will lose $65 \%$ of its climatically suitable habitats due to climate change in 2080 , while $13.94 \%$ of current unsuitable habitats will become suitable. Thus, its habitat will shrink by $51 \%$. Most of habitat loss will be in the plains and almost all of habitat gain, is on the highlands.
\end{abstract}

Keywords: ecological niche; species distribution models, habitat modeling, Poaceae, BIOMOD

\section{Introduction}

Climate is known as the long-term average weather of a region (IPCC, 2001). A change in this average generally occurs in two forms: short-term fluctuations that are random and long-term changes that follow a specific trend. The latter is known as climate change and, in recent decades, has greatly increased in intensity. Many scientists regard global warming as the result of human activities and believe that these changes could largely affect the lives of many organisms (IPCC, 2007). Ecological modeling of species is among the methods that can monitor these effects and determine their dimensions. The results obtained from the modeling can be very useful in various managerial decisions (Araujo and Guisan, 2006). One of the major effects caused by changes in environmental conditions in general and climate changes in particular can have on plant life is the alteration in the geographical distribution (Lawler et al., 2006). Since plants cannot move fast and individually, they respond to environmental changes with a relatively long delay; they move in the geographical environment after climate change in order to find the environmental conditions, which are more suitable to their life (Iverson and McKenzie, 2013). Many studies have been dedicated to examining the dimensions and orientation of these changes. After investigating effects of climate change on a species of dragonfly, Attorre et al. (2007) concluded that climate changes could have dramatic effects on the biological ability of species in their habitat. Collevatti et al. (2011) studied the effect of climate change on a tree species and 
expressed that climate change could cause loss in the parts of habitats and, subsequently, genetic diversity at the subspecies level. King et al. (2013) conducted their study on several species in ecotone between grassland and shrubland, in which they used dynamic vegetation model to measure and investigate the movement of distribution range of their studied species as a result of climate change. Morin and Thuiller (2009) compared different modeling methods and tried to maximize the efficiency of the models predicting movement degree of species due to climate change and finished their work by introducing process-driven models as the best models. Many studies have concluded that climate changes cause variations in geographical and spatial distribution of species; therefore, planning is needed to protect and revive these species. Aurambout et al. (2009) studied the effect of climate change on the spatial distribution of a citrus species in Australia and concluded that this species would undergo environmental stress as a result of climate change, which would restrict its life. They then concluded that, to maintain this species, specific measures should be taken. Zimbres et al. (2012) studied climate change and emphasized the role of protected areas in the conservation and maintenance of insectivorous species of armadillo and anteater. In one of the pioneering studies on the effect of climate change on the geographical distribution of species, Peterson et al. (2001) studied Curassow bird in the Central America and concluded that, if climate change continues at the current intensity, this beautiful species would face serious problems to survive in the region. Keith et al. (2008) investigate the extinction risk of different species as a result of climate change and concluded that most of their studied species would suffer from reduction in their climate distribution range as a result of climate change and some of them would be even placed at the risk of extinction. In one of the largest studies on the effect of climate change on species survival, Thuiller et al. (2005) examined 1350 plant species in Europe using 7 climate change scenarios and concluded that climate change could be a threat to plant biodiversity in Europe.

Nevertheless, regarding the considerable biodiversity, there is urgent need to conduct studies of these kinds in Iran, especially for pasture plant species. This study was carried out in a semi-arid region (Central Zagros) in Iran and aimed investigate the potential impacts of change of the climate components on the geographical distribution of an important forage species in these pastures.

\section{Materials and Methods}

\section{Studied species and region}

Bromus tomentellus Boiss. which belongs to Gramineae family, Pooideae sub-family, and Bromeae tribe (Fitter and Peat, 1994), is a perennial grass with a splay root and numerous leaves which are covered by white and dens fluff. Its global distribution is limited to western Asia and flora Iranica (Rechinger, 1963-1998) describe it as a semisteppe to steppe species which is found in 1500 to 3400 meters elevation. This species lives in rocky lands and freely disperse its root in the soil (Fitter and Peat, 1994). B. tomentellus establishes in different soil textures and have a significant role in runoff reduction, but cannot stand the salinity of the soil (Armaki et al., 2013). Elevation, precipitation and temperature are the most important environmental factors affecting this species. In Isfahan province (part of Central Zagros region), this species can be find from 1900 to 3700 meters of elevation in semi steppe habitats. The precipitation of its habitats range from 200 to $450 \mathrm{~mm}$ which can alter regarding microclimate. Its populations are 
more dense in the plains in comparison with mountains (Eftekhari et al., 2007). This plant is one of the important grasses of semi-steppe pastures in Iran (Mesdaghi, 2003). This species grows in the areas with the rainfall of about $400 \mathrm{~mm}$, and tolerates the minimum rainfall of $250 \mathrm{~mm}$. Forage yield of this species depends on annual rainfall and its distribution (Eftekhari et al., 2007) (Fig. 1).

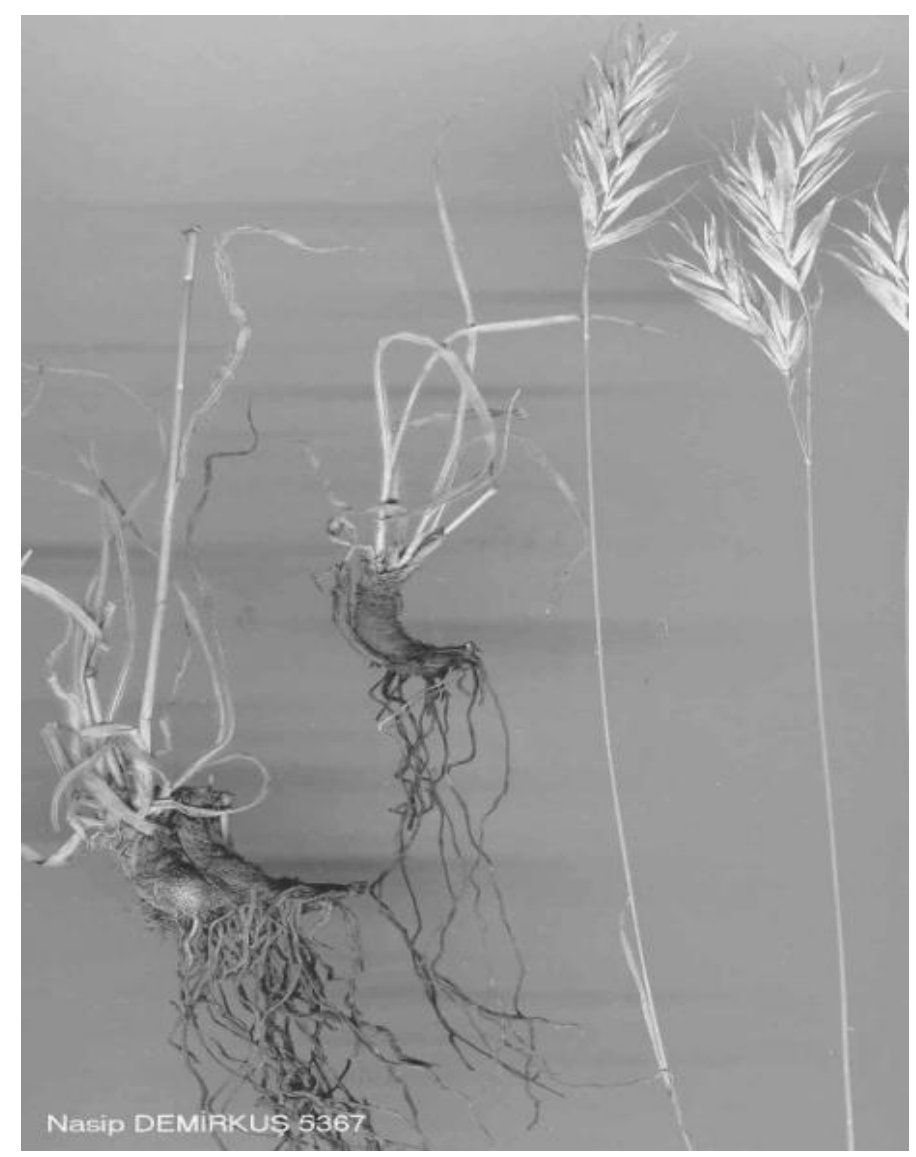

Figure 1. Bromus tomentellus

The studied region in this research had the area of 2202659 ha in the central part of Zagros Mountains, which is very important in terms of biodiversity and ecological value (UNDP and GEF, 2005). Also, this region is economically and socially important for the nomadic and rural communities who use its pastures for grazing their livestock (Fig. 2 ). Field studies including harvest of geographical coordinates of the presence of this species in Central Zagros were conducted in spring 2014 and 2015. 


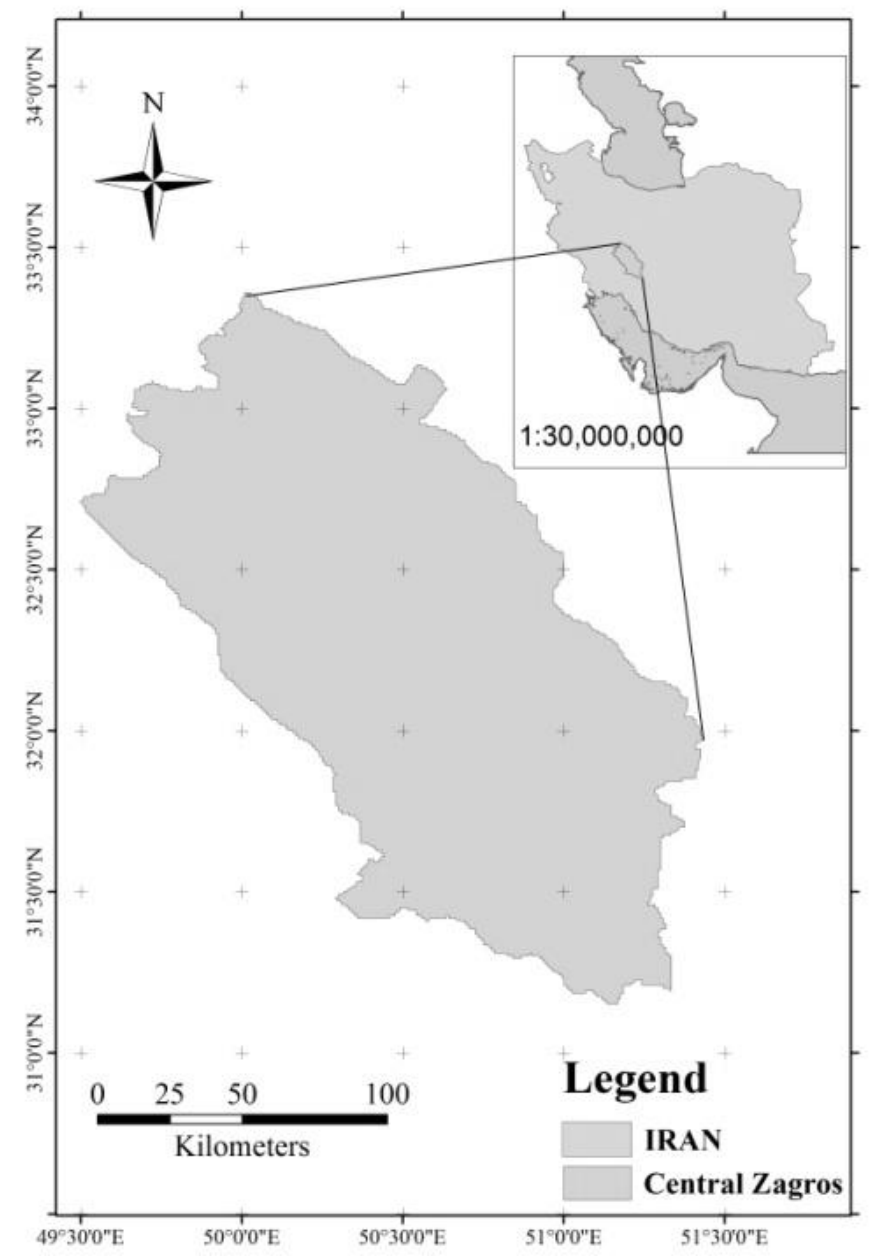

Figure 2. Central Zagros region, Iran

\section{Climatic variables}

In this study, 19 bioclimatic variables (Hijmans et al., 2005) were used as climate factors describing Bromus tomentellus habitat, which have been applied in many studies as the basis for monitoring effects of climate change on organisms (especially, plants) (Xu, 2014; Thuiller et al., 2005). These variables are mainly influenced by season, temperature, and rainfall; therefore, despite their climatic nature, they are also ecologically significant. Table 1 describes these variables. 
Table 1. Description of bioclimatic variables

\begin{tabular}{|c|c|c|c|}
\hline Abbreviation & Description & Abbreviation & Description \\
\hline BIO1 & Annual Mean Temperature & BIO11 & $\begin{array}{l}\text { Mean Temperature of Coldest } \\
\text { Quarter }\end{array}$ \\
\hline $\mathrm{BIO} 2$ & $\begin{array}{l}\text { Mean Diurnal Range (Mean of monthly } \\
\text { (max temp - min temp)) }\end{array}$ & BIO12 & Annual Precipitation \\
\hline $\mathrm{BIO} 3$ & Isothermality (BIO2/BIO7) $(* 100)$ & $\mathrm{BIO} 13$ & Precipitation of Wettest Month \\
\hline $\mathrm{BIO} 4$ & $\begin{array}{l}\text { Temperature Seasonality (standard } \\
\text { deviation } * 100 \text { ) }\end{array}$ & $\mathrm{BIO} 14$ & $\begin{array}{l}\text { Precipitation of Driest Month } \\
\text { Precipitation Seasonality }\end{array}$ \\
\hline $\mathrm{BIO} 5$ & Max Temperature of Warmest Month & BIO15 & (Coefficient of Variation) \\
\hline $\mathrm{BIO6}$ & $\begin{array}{l}\text { Min Temperature of Coldest Month } \\
\text { Temperature Annual Range (BIO5- }\end{array}$ & BIO16 & Precipitation of Wettest Quarter \\
\hline $\mathrm{BIO} 7$ & BIO6) & BIO17 & Precipitation of Driest Quarter \\
\hline $\mathrm{BIO} 8$ & Mean Temperature of Wettest Quarter & BIO18 & Precipitation of Warmest Quarter \\
\hline BIO9 & Mean Temperature of Driest Quarter & BIO19 & Precipitation of Coldest Quarter \\
\hline BIO10 & Mean Temperature of Warmest Quarter & & \\
\hline
\end{tabular}

Modified from: www.worldclim.org

Indeed, it should be noted that, considering that the correlation between input variables to the used models can cause considerable error in the output of the models (Braunisch et al., 2013), first, the existence of correlation between bioclimatic variables modified by Pearson test was examined and the layers with more than $80 \%$ correlation with each other were determined. To solve this problem, some of them (based on correlation degree) were removed and this process was repeated until the correlation between the remaining layers reached below the specified limit.

\section{Used models}

The information presented here are largely borrowed and modified from Marmion et al. (2009); we have explored all the references though.

\section{Generalized Linear Models}

GLM was introduced to statistics by Nelder and Wedderburn (1972). McCullagh and Nelder (1989) describe a GLM as a mathematical extension of linear models. These models are not sensitive to different types of statistical distributions and are suitable for nonlinear relationships; besides, they use traditional practices used in linear modelling and analysis of variance (ANOVA). In this study we used biomod2 to run a stepwise GLM were akaike value to compute the best model (Thuiller, 2003).

\section{Flexible Discriminant Analysis}

Flexible discriminant analysis (FDA) is a method that uses linear discriminant analysis (LDA) developed by Fisher (1936) as the basis. In LDA, it is possible to choose several optimal variables from a large number of variables to determine and separate the groups available in the response variable. LDA performs this task by multiple linear regressions; but, if nonlinear equations dominate a relationship, it will face a problem. Therefore, Hasti et al. (1994) used a flexible series of equations rather than linear equations to fit the values. Using this flexibility, linear equations are not the only equations that are fitted and tested on the data, but also other types of equations (quadratic, cubic, logarithmic, etc.) are used and, finally, the best equation is selected. 


\section{Classification Tree Analysis}

CTA is an alternative to regression techniques and has been used rather often in biogeographical and environmental studies (Franklin, 2002). CTA uses recursive partitioning to split the data into increasingly smaller, homogenous, subsets until a termination is reached (Venables and Ripley, 2002). The optimal length of the tree is selected by a 50 -fold crossvalidation. The advantage of CTA is that it allows capturing of non-additive behaviour and complex interactions. However, CTA has a tendency to produce overlycomplex models that lead to spurious interpretations (Breiman et al., 1984). CTA is used frequently for biogeographical and environmental studies (De'Ath and Fabricius, 2000; Vayssière et al., 2000; Franklin, 2002; Thuiller, 2004).

\section{General Boosting Method}

GBMs were recently introduced in ecology. They are highly efficient in fitting the data, are non-parametric and combine the strengths of different modern statistical techniques (Ridgeway, 1999). Here, GBM was implemented into R (R Development Core Team, 2004) using the library GBM (Generalized Boosted Regression Modelling). GBM is based on the Gradient Boosting Machine developed by Friedman (2001). GBM proceeds via sequential improvements. Boosting is a numerical optimization technique for minimizing a loss function (such as deviance) by adding at each step a new tree that best reduces the loss function (Ridgeway, 1999; Elith et al., 2008). Environmental variables are input into a first regression tree, which maximally reduces the loss function. For each following step, the focus is on the residuals. For example, at the second step a tree is fitted to the residuals of the first tree. The model is then updated to contain two trees, and the residuals from these two trees are calculated. The sequence is repeated as long as necessary (Elith et al., 2008). The maximum number of trees was set to 3000 , and ten-fold cross validations were performed. GBM belongs to the class of learning methods.

\section{Surface Range Envelope}

Statistical bases of SRE method, which is also known as BIOCLIM, were first founded by Nix in 1986 (Nix, 1986). This method is a distributed-centered algorithm that extracts the values of climate layers corresponding to the presence points of species and cumulatively sorts them. The set of values of all climatic layers corresponding to presence points of species constituents the so-called climatic "envelope" of species (climatic conditions including all presence parts of the species). Many studies have pointed out the statistical foundations of modeling and statistical limitations of the method (Fisher et al., 2001; Guisan and Zimmermann, 2000; Walther et al., 2004; Ward, 2007), and in some other studies, this method has been introduced as an appropriate method for modeling species distribution scope and niche (Elith et al., 2006; Hijmans and Graham, 2006).

\section{Random Forest}

RF belongs to the machine learning methods (Breiman, 2001). Random Forest generates hundreds of random trees. A selective algorithm limits the number of implemented parameters in each tree. A training set for each tree is chosen as many times as there are observations, among the whole set of observations. For each node of 
trees, the decision is taken according to randomly selected environmental parameters. Trees thus constructed are not pruned and are as large as possible. After the trees have been built, data are entered into them and each grid square will be classified by all trees. At the end of the run, the classification given by each tree is considered as a "vote", and the classification of a grid square corresponds to the majority vote among all trees (Breiman, 2001). RF was used by Prasad et al. (2006) for vegetation mapping under current and future climate scenarios.

\section{Multivariate Adaptive Regression Splines}

MARS combines classical linear regression, mathematical construction of splines and binary recursive partitioning to produce a local model in which relationships between response and predictors are either linear or nonlinear (Friedman, 1991). A preprocessing algorithm of the explanatory variables uses the basic functions (BF) max $(0, X-c)$ and $\max (0, c-X)$ to transform the environmental variables into a new set of variables. The main difficulty is to find appropriate " $c$ " values, but a suitable choice makes it possible to approximate any functional shape (Briand et al., 2004). Then, MARS performs successive approximation of the system using different intervals of the transformed variables ranges, by a series of linear regressions. Examples of the use of MARS in biogeographical studies can be found in several articles (Muñoz and Felicísimo, 2004; Corte-Real et al., 1995; Heikkinen et al., 2007).

\section{Artificial Neural Networks}

ANN is a powerful rule-based modelling technique (Lek and Guegan, 1999), which is increasingly used in bioclimatic envelope modelling (Thuiller, 2003; Heikkinen et al., 2006). A network contains three different types of layers: the input layer (in which the environmental variables are input), the hidden (intermediate) layers and the output layer. Each layer is composed of independent neurons; each of them treats separately the outputs of all neurons from the previous layer as inputs of multivariate linear functions. The process is continued until processing of the output layer. To avoid over fitting in neural networks, a fourfold cross-validation method was implemented to stop training of networks. Once the complete network is built, the different weighting factors of the multivariate linear functions are chosen by minimizing the quadratic error of estimate (Marmion et al., 2009).

After calibration of models, their results used for evaluation purposes. Confusion matrix has been built and using classic equations, the area under the curve (AUC) of a receiver operating characteristic (ROC) plot of each model was calculated. Marmion et al. (2009) described this method as: "AUC is a graphical method assessing the ability of a model to predict the absence or presence of species on the basis of given criteria (e.g. climate variables), by representing the relationship between the false positive fraction and the true positive fraction of the related confusion matrix of the evaluated model (Fielding and Bell, 1997)."

The applied models were implemented by biomod2 in $\mathrm{R}$ environment (Thuiller, 2003). To do so, $20 \%$ of the species presence data was devoted to the evaluation and $80 \%$ to the implementation of these models (finding the relationships between the species and environment). Also, the prevalence amount was considered equal to 0.5 in these models, which is a common practice in determining prevalence (McPherson et al., 2004; Liu et al., 2005). This process was repeated for 10 times for each of the used 
models; at each time, evaluation and implementation parts were randomly selected from the data. Finally, for each model, the results were obtained from these 10 runs.

\section{Results}

After conducting Pearson's correlation analysis and removing layers with high correlation, it was found that 8 layers (BIO8, BIO2, BIO3, BIO4, BIO12, BIO14, BIO15 and BIO18) were not highly correlated with each other and can be used to enter the final model.

To assess the accuracy of the maps produced by the model, AUC of ROC plot was used (Table 2). This index were calculated and reported in two parts: sensitivity (probability of species presence in a place that is present in the reality) and specificity (probability of expressing the absence of the species in a place that is absent in the reality).

Table 2. AUC, Sensitivity and Specificity of applied models

\begin{tabular}{llllllllll}
\hline Model & & ANN & CTA & FDA & GBM & GLM & MARS & RF & SRE \\
\hline \multirow{4}{*}{ AUC } & Value & 0.891 & 0.798 & 0.842 & 0.969 & 0.858 & 0.87 & 0.999 & 0.762 \\
& Sensitivity & 95.312 & 95.312 & 82.812 & 93.75 & 87.5 & 76.562 & 100 & 76.562 \\
& Specificity & 78.958 & 64.249 & 74.259 & 91.624 & 75.996 & 83.146 & 98.979 & 75.894 \\
\hline
\end{tabular}

Based on these results, all models are functioning good, because whenever an implemented model has the AUC values of more than 0.7 and 0.9 , it will be considered a good and excellent model, respectively; otherwise, the model is weak (Swets, 1988). Also, relative contribution of each of the input variables to the models in predicting suitable sites for the species presence is shown in Table 3.

Table 3. Importance of each climatic variable in the used models for studying Bromus tomentellus geographic distribution

\begin{tabular}{lcccccccc}
\hline \multicolumn{8}{c}{ Importance of each climatic variable in models } \\
\hline Variable & ANN & CTA & FDA & GBM & GLM & MARS & RF & SRE \\
BIO12 & 0.34 & 0.47 & 0.18 & 0.51 & 0.38 & 0.2 & 0.31 & 0.28 \\
BIO14 & 0 & 0 & 0 & 0 & 0 & 0 & 0 & 0.001 \\
BIO15 & 0.04 & 0 & 0 & 0.06 & 0 & 0.23 & 0.06 & 0.18 \\
BIO18 & 0.12 & 0 & 0 & 0.006 & 0.03 & 0.018 & 0.10 & 0.04 \\
BIO2 & 0.11 & 0 & 0.25 & 0.03 & 0.08 & 0.15 & 0.10 & 0.10 \\
BIO3 & 0.006 & 0 & 0.10 & 0.02 & 0.09 & 0.07 & 0.06 & 0.12 \\
BIO4 & 0.09 & 0 & 0.20 & 0.025 & 0.14 & 0.17 & 0.10 & 0.027 \\
BIO8 & 0.29 & 0.53 & 0.27 & 0.35 & 0.27 & 0.16 & 0.26 & 0.24 \\
\hline
\end{tabular}

Maps in Figure 3 show the suitable regions predicted for the species by each of the used 8 models. 

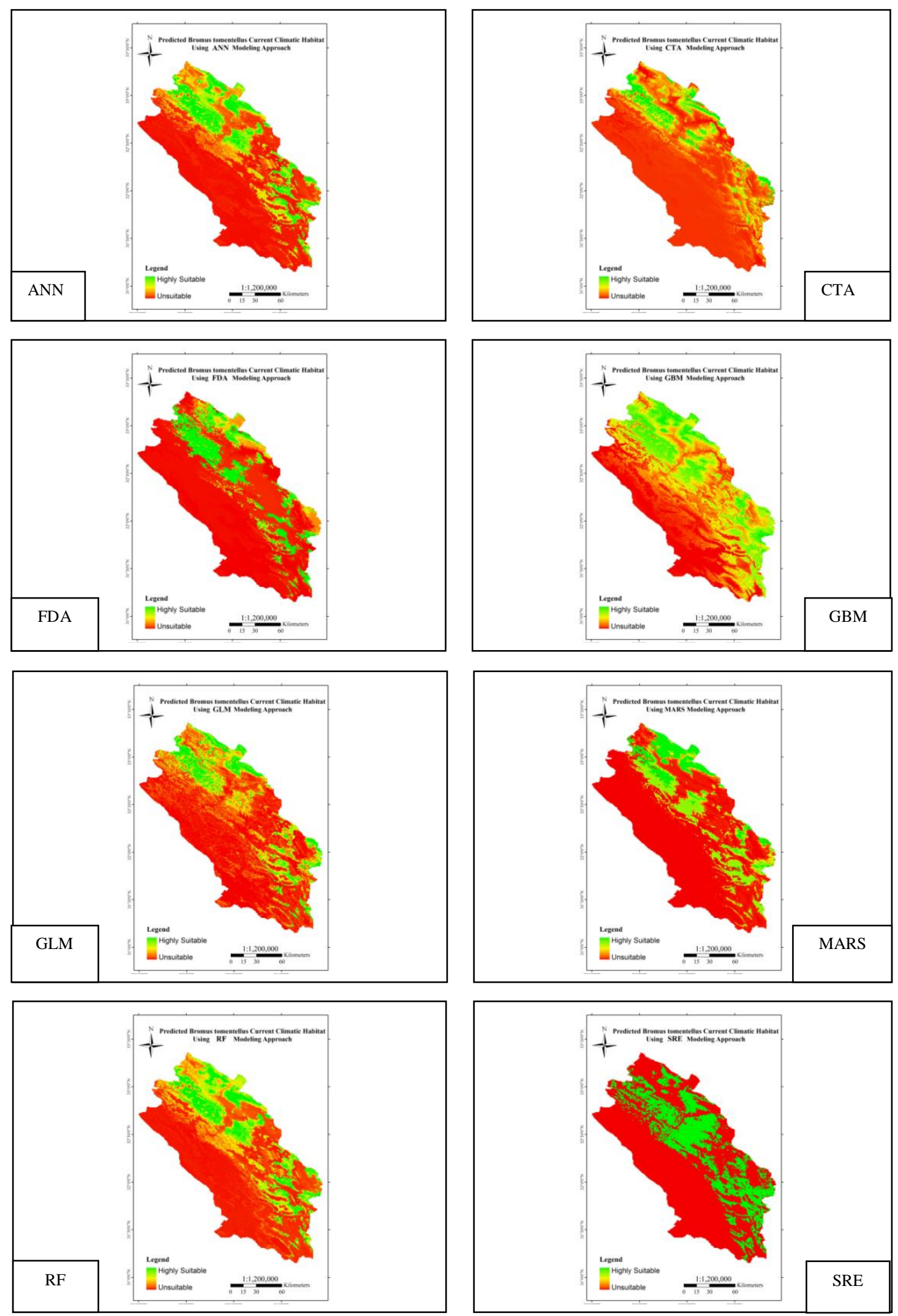

Figure 3. Current Bromus tomentellus geographical distribution based on climatic variables using different models 
Finally, to obtain a general conclusion about the requirements and suitable regions for the species presence, results of the models that were appropriate in terms of assessment (all models) were summed up using consensus technique and the environmental needs of the studied species (Table 4) along with a single map of suitable regions for distribution were prepared.

Table 4. Niche characteristics of Bromus tomentellus in Central Zagros

\begin{tabular}{lcc}
$\begin{array}{l}\text { Climatic variables affecting } \\
\text { Bromus tomentellus habitat }\end{array}$ & $\begin{array}{c}\text { Occurrence range of species in } \\
\text { variable }\end{array}$ & $\begin{array}{c}\text { Relative contribution in } \\
\text { describing suitable } \\
\text { climatic habitat }(\%)\end{array}$ \\
\hline
\end{tabular}

Annual Precipitation (BIO12)

Mean Temperature of Wettest Quarter (BIO8)

Precipitation Seasonality

(BIO2)

Temperature Seasonality
$315-420 \mathrm{~mm}$

33

$-5.5-0.0^{\circ} \mathrm{C}$

30

$15-16{ }^{\circ} \mathrm{C}$

10 (BIO4) $8270-8650$ (standard deviation $* 100$ )
10

\section{Geographical distribution maps of the species}

By studying climate change in different time periods, species distribution maps in these periods were developed based on the climatic requirements. These maps were prepared for the present period and 2080. Figure 4 indicates the two relative suitability maps of habitats for Bromus tomentellus in the studied time periods.
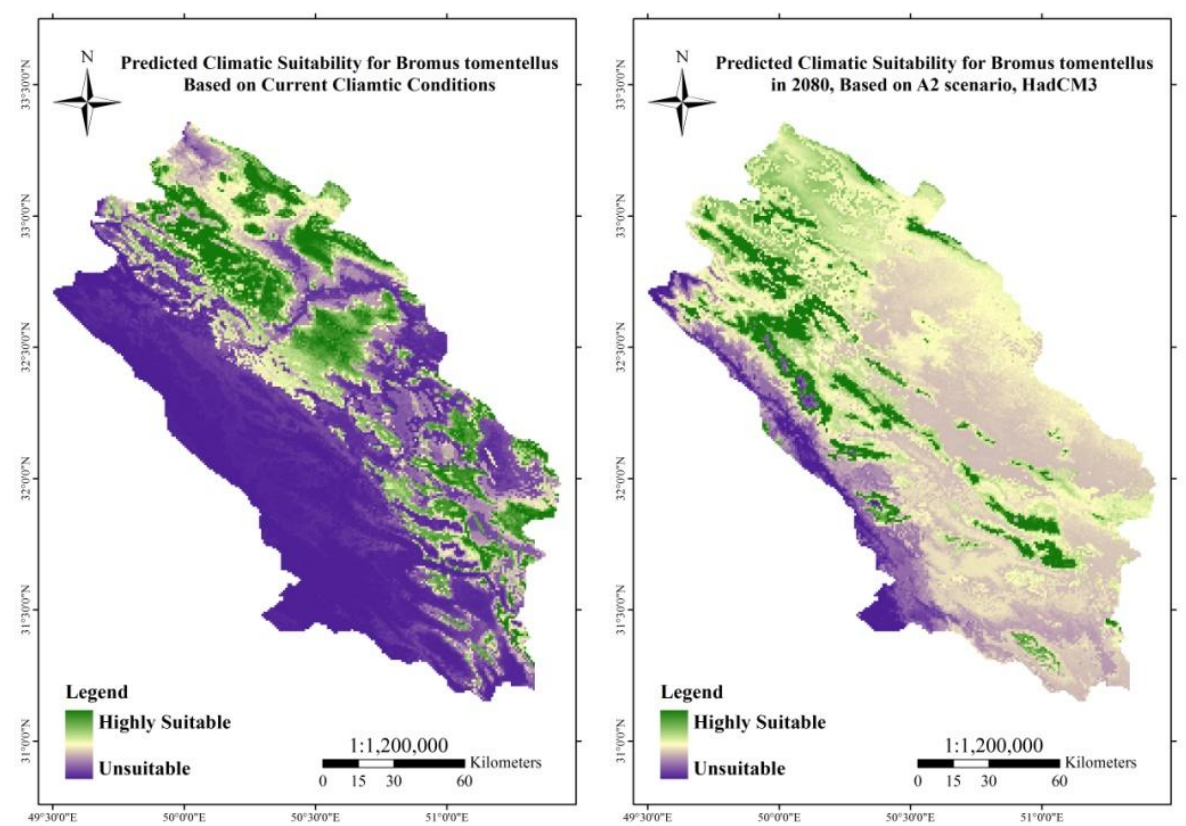

Figure 4. Consensus map of relative suitability of Bromus tomentellus climate conditions (Right: Present time, Left: 2080) 


\section{Changes in Bromus tomentellus geographical distribution}

To investigate the impact of climate change on the geographic distribution of species, first, a critical level was used (calculated based on ROC criteria) to classify habitat suitability maps into two classes of appropriate and inappropriate and, then, the difference in each of these two classes was calculated and prepared as a table and a map (Table 5, Fig. 5).

Table 5. Changes in the geographic distribution of the studied species in the time steps

\begin{tabular}{|c|c|c|c|c|c|c|c|c|c|}
\hline & $\begin{array}{c}\text { Base } \\
\text { Layer } \\
\text { Presence } \\
\text { (ha) }\end{array}$ & $\begin{array}{c}\text { Base } \\
\text { Layer } \\
\text { Absence } \\
\text { (ha) }\end{array}$ & $\begin{array}{c}\text { Stable } \\
\text { Presence } \\
\text { (ha) }\end{array}$ & $\begin{array}{c}\text { Stable } \\
\text { Absence } \\
\text { (ha) }\end{array}$ & $\begin{array}{c}\text { Lost } \\
\text { Habitat } \\
\text { (ha) }\end{array}$ & $\begin{array}{c}\text { Gained } \\
\text { habitat } \\
\text { (ha) }\end{array}$ & $\begin{array}{l}\text { Habitat } \\
\text { Loss } \\
\text { (Percent) }\end{array}$ & $\begin{array}{c}\text { Habitat } \\
\text { Gain } \\
\text { (Percent) }\end{array}$ & $\begin{array}{l}\text { Habitat } \\
\text { Change } \\
\text { (Percent) }\end{array}$ \\
\hline $\begin{array}{c}\text { Current vs } \\
\text { A2 } 2080\end{array}$ & 731248 & 1471411 & 252909 & 1369452 & 478339 & 101959 & 65.41 & 13.94 & -51.47 \\
\hline
\end{tabular}

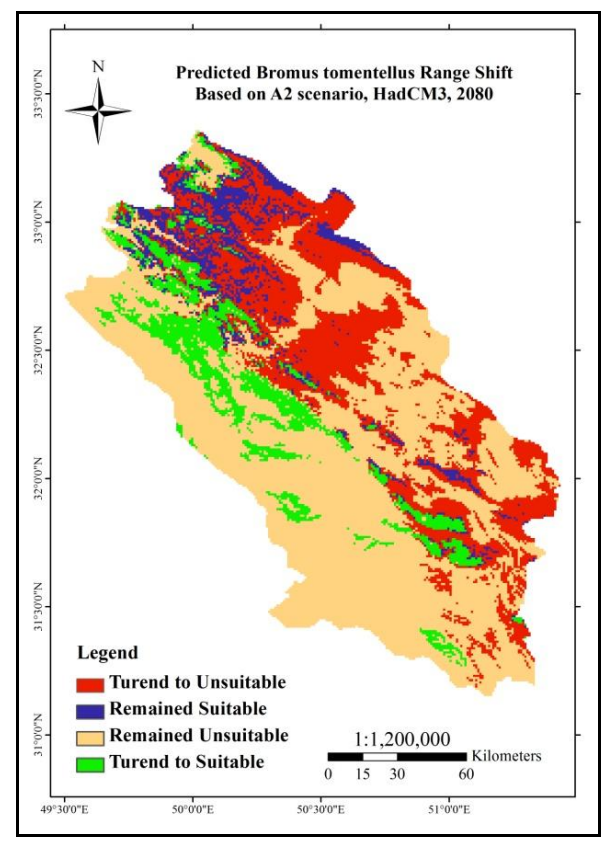

Figure 5. Changes of suitable geographical scope for Bromus tomentellus in the present climate conditions compared with 2080

\section{Discussion and Conclusion}

Results of the study were highly consistent with those of autecological studies that have been previously done on this species as far as determining the climate needs of Bromus tomentellus was concerned. For example, Saboohi and Khodagholi (2013) studied climatic needs of $B$. tomentellus and concluded that precipitation and cold season temperature are the most important factors affecting this species, similar results were also obtained in the present study. Results of this study showed that, in the studied region, Bromus tomentellus was moved toward the west as a result of climate changes (which generally has higher elevation). To be precise, we can say that the average height of the regions in which the species was present was 2,550 m. But, based on our modeling results, this value was stated as 2700 meters in 2080 (in A2 scenario). Similar results have been also obtained in many of the studies in which the movement of species 
influenced by climate change has been studied. In an article published in Nature, Thuiller (2007) stated that the climate change will cause the movement of plant and animal species to the $160 \mathrm{~m}$ higher elevations, by average. A study that was conducted on plant communities located in the southwest region of the United States showed that most of the plant communities were moved pole ward or to the heights in response to climate changes (Archer and Predick, 2008). Stenothermic species which are present in the places that cannot move to higher altitudes, can sustain maximum damage by climate change (Anderson, 2013). Bakkenes et al. (2002) studied higher plants in Europe and found similar results. The studied species was a cool-season grass species with a relatively wide ecological niche, but it will be forced to shift its geographic range as a result of climate change.

\section{Three-dimensional space of the most important climate conditions related to the species}

To define the ecological niche of Bromus tomentellus in Central Zagros, concept of Hutchinson's ecological niche was used (Hutchinson, 1957). The three climatic components affecting the species were depicted in a three-dimensional space and the suitable ecological situation was determined for this species in this space (Figs. 6 and 7 , respectively).

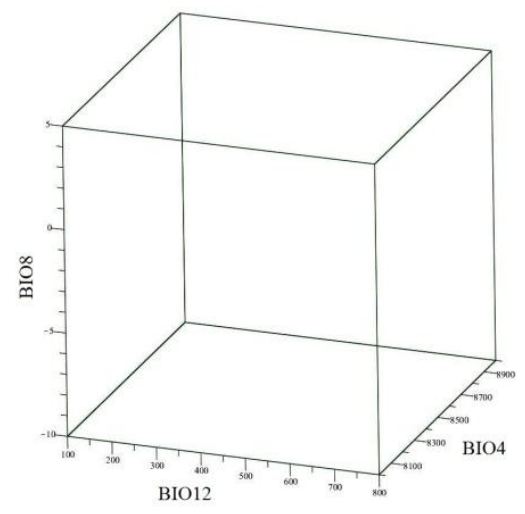

Figure 6. Three-dimensional space of climatic conditions in the whole studied region

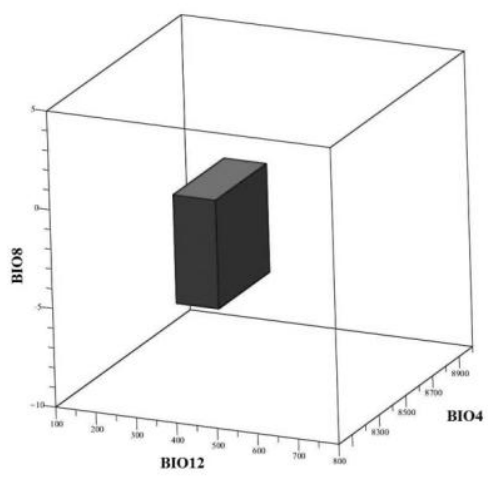

Figure 7. Position of Bromus tomentellus ecological niche in three-dimensional space of climatic conditions 
The Bromus tomentellus ecological position in the three-dimensional space of the environmental variables reflected its tolerance range against three components of this space. The more the number of the ecological environment dimensions of environmental variables, the more accurate the Bromus tomentellus ecological niche would be determined. Thus, complete ecological niche of each species could be determined in an environmental hyper volume (Hutchinson, 1957).

According to the results obtained in this study, large changes are expected to happen in the distribution of this species along with climate change. These changes are in a way that could limit the suitable climatic conditions for the life of this important and effective species in the studied region. Therefore, to improve the conditions, the least thing that can be done is to control the destruction of Bromus tomentellus habitat through managing livestock grazing and preventing the landuse change of pastures. If we do so, we can hope that climate change cannot excessively attenuate or even completely eliminate this valuable species from the regional flora by itself and maybe physiological, phenological, and morphological adaptations of this species would help it fight the climate changes.

\section{REFERENCES}

[1] Anderson, R. P. (2013): A framework for using niche models to estimate impacts of climate change on species distributions. - Annals of the New York Academy of Sciences 1297:8-28.

[2] Araujo, M. B., Guisan, A. (2006): Five (or so) challenges for species distribution modelling. Journal of Biogeography 33:1677-88.

[3] Archer, S. R., Predick, K. I. (2008): Climate change and ecosystems of the southwestern United States. - Rangelands 30:23-8.

[4] Armaki, M. A., Hashemi, M., Azarnivand, H. (2013): Physiological and Morphological Responses of Three Bromus Species to Drought Stress at Seedling Stage and Grown under Germinator and Greenhouse Conditions. - African Journal of Plant Science 7:155-61.

[5] Attorre F., Francesconi, F., Taleb, N., Scholte, P., Saed, A., Alfo, M., Bruno, F. (2007): Will dragonblood survive the next period of climate change? Current and future potential distribution of Dracaena cinnabari (Socotra, Yemen). - Biological Conservation 138:430-9.

[6] Aurambout, J., Finlay, K., Luck, J., Beattie, G. (2009): A concept model to estimate the potential distribution of the Asiatic citrus psyllid in Australia under climate change-A means for assessing biosecurity risk. - Ecological Modelling 220:2512-24.

[7] Bakkenes, M., Alkemade, J., Ihle, F., Leemans, R., Latour, J. (2002): Assessing effects of forecasted climate change on the diversity and distribution of European higher plants for 2050. - Global Change Biology 8:390-407.

[8] Braunisch, V., Coppes, J., Arlettaz, R., Suchant, R., Schmid, H., Bollmann, K. (2013): Selecting from correlated climate variables: a major source of uncertainty for predicting species distributions under climate change. - Ecography 36:971-83.

[9] Breiman, L. (2001): Random forests. - Machine Learning 45:5-32.

[10] Breiman, L., Friedman, J. H., Olshen, R. A., Stone, C. I. (1984): Classification and regression trees. - Taylor \& Francis, California.

[11] Briand, L. C., Freimut, B., Vollei, F. (2004): Using multiple adaptive regression splines to support decision making in code inspections. - The Journal of Systems and Software, 73:205-17.

[12] Collevatti, R. G., Nabout, J. C., Diniz-Filho, J. A. F. (2011): Range shift and loss of genetic diversity under climate change in Caryocar brasiliense, a Neotropical tree species. -Tree Genetics \& Genomes 7:1237-47. 
[13] Corte-Real, J., Zhang, X., Wang, X. (1995): Downscaling GCM information to regional scales: a non-parametric multivariate regression approach. - Climate dynamics 11:413-24.

[14] De'ath, G., Fabricius, K. E. (2000): Classification and regression trees: a powerful yet simple technique for ecological data analysis. - Ecology 81:3178-92.

[15] Eftekhari, M., Feyzi, M. T., Khoda Qoli, M., Shirani, K. (2007): Study on the Autecology of Bromus tomentellus in Esfahan province. Research Report. - Reseach Institute of Forest and Rangeland, Karaj, Iran.

[16] Elith, J., Graham, C. H., Anderson, R. P., Dudik, M., Ferrier, S., Guisan, A., Hijmans, R. J., Huettman, F., Leathwick, J. R., Lehmann, A., Li, J., Lohmann, L., Loiselle, B., Manion, G., Moritz, C., Nakamura, M., Nakazawa, Y., Overton, J. M., Peterson, A. T. , Phillips, S. J., Richardson, K. S., Scachetti-Pereira, R., Schapire, R. E., Soberon, J., Williamson, S., Wisz, M. S., Zimmermann, N. E. (2006): Novel methods improve prediction of species' distributions from occurrence data. - Ecography 29:129-51.

[17] Elith, J., Leathwick, J. R., Hastie, T. (2008): A working guide to boosted regression trees. Journal of Animal Ecology 77:802-13.

[18] Fielding, A. H., Bell, J. F. (1997): A review of methods for the assessment of prediction errors in conservation presence/absence models. - Environmental Conservation 24:38-49.

[19] Fisher J., Lindenmayer, D. B., Nix, H. A., Stein, J. L., Stein, J. A. (2001): Climate and animal distribution: a climatic analysis of the Australian marsupial Trichosurus caninus. - Journal of Biogeography 28:293-304.

[20] Fisher, R. A. (1936): The use of multiple measurements in taxonomic problems. - Annals of Eugenics 7:179-88.

[21] Fitter, A. H., Peat, H. J. (1994): The Ecological Flora Database. - Ecology 82 415-25.

[22] Franklin, J. (2002): Enhancing a regional vegetation map with predictive models of dominant plant species in chaparral. - Applied Vegetation Science 5:135-46.

[23] Friedman, J. H. (1991): Multivariate adaptive regression splines. - The Annals of Statistics 19:1-67.

[24] Friedman, J. H. (2001): Greedy function approximation: a gradient boosting machine.- The Annals of Statistics 29:1189-232.

[25] Guisan, A., Zimmermann, N. E. (2000): Predictive habitat distribution models in ecology. Ecological Modelling 135:147-86.

[26] Hastie, T., Tibshirani, R., Buja, A. (1994): Flexible Discriminant Analysis by Optimal Scoring. - Journal of American statistical association 89:1255-70.

[27] Heikkinen, R. K., Luoto, M., Araújo, M. B., Virkkala, R., Thuiller, W., Sykes, M. T. (2006): Methods and uncertainties in bioclimatic envelope modelling under climate change. Progress in Physical Geography 30:751-77.

[28] Heikkinen, R. K., Luoto, M., Toivonen, T., Kuussaari, M. (2007): Effects of model complexity, spatial resolution and modelling technique on distribution modelling of a threatened butterfly. - Landscape and Urban Planning 79:347-57.

[29] Hijmans, R. J., Cameron, S. E., Parra, J. L., Jones, P. G., Jarvis, A. (2005): Very high resolution interpolated climate surfaces for global land areas. - International journal of climatology 25:1965-78.

[30] Hijmans, R. J., Graham, C. H. (2006): The ability of climate envelope models to predict the effect of climate change on species distributions. - Global Change Biology 12:2272-81.

[31] Hutchinson, G. E. (1957): Concluding remarks. - Cold Spring Harbor Symp Quantative Biology 22:415-27.

[32] IPCC (2001). Climate Change 2001: The Scientific Basis. Contribution of Working Group I to the Third Assessment Report of the Intergovernmental Panel on Climate Change. Cambridge University Press, New York.

[33] IPCC (2007). Climate change 2007: The physical science basis. - Agenda 6:333.

[34] Iverson, L. R., Mckenzie, D. (2013): Tree-species range shifts in a changing climate: detecting, modeling, assisting. - Landscape Ecology 28:879-89. 
[35] Keith, D. A., Akçakaya, H. R., Thuiller, W., Midgley, G. F., Pearson, R. G., Phillips, S. J., Regan, H. M., Araújo, M. B., Rebelo, T. G. (2008): Predicting extinction risks under climate change: coupling stochastic population models with dynamic bioclimatic habitat models. Biology Letters 4:560-3.

[36] King, D. A., Bachelet, D. M., Symstad, A. J. (2013): Climate change and fire effects on a prairie-woodland ecotone: projecting species range shifts with a dynamic global vegetation model. - Ecology and Evolution 3:5076-97.

[37] Lawler, J. J., White, D., Neilson, R. P., Blaustein, A. R. (2006): Predicting climate-induced range shifts: model differences and model reliability. - Global Change Biology 12:1568-84.

[38] Lek, S., Guegan, J. (1999): Artificial neural networks as a tool in ecological modelling, an introduction. - Ecological Modelling 120:65-73.

[39] Liu, C., Berry, P. M., Dawson, T. P., Pearson, R. G. (2005): Selecting thresholds of occurrence in the prediction of species distributions. - Ecography 28:385-93.

[40] Marmion, M., Luotoa, M., Heikkinenc, R. K., Thuiller, W. (2009): The performance of stateof-the-art modelling techniques depends on geographical distribution of species. - Ecological Modelling 220 3512-20.

[41] Mccullagh, P., Nelder, J. A. (1989): Generalized linear models. - Chapman and Hall, London.

[42] Mcpherson, J. M., Jetz, W., Rogers, D. J. (2004): The effects of species' range sizes on the accuracy of distribution models: ecological phenomenon or statistical artifact? - Journal of Applied Ecology 41:811-23.

[43] Mesdaghi, M. (2003): Range management in Iran. - Imam Reza University Press, Mashhad, Iran.

[44] Morin, X., Thuiller, W. (2009): Comparing niche-and process-based models to reduce prediction uncertainty in species range shifts under climate change. - Ecology 90:1301-13.

[45] Muñoz, J., Felicísimo, A. (2004): Comparison of statistical methods commonly used in predictive modelling. - Journal of Vegetation Science 15:285-92.

[46] Nelder, J. A., Wedderburn, R. (1972): Generalized linear models. - Journal of the Royal Statistical Society 135:370-84.

[47] Nix, H. A. (1986): A biogeographic analysis of Australian elapid snakes. - In: Longmore, R. (ed.) Atlas of Elapid Snakes of Australia, Australian Government Pub, Australia.

[48] Peterson, A. T., Sánchez-Cordero, V., Soberón, J., Bartley, J., Buddemeier, R. W., NavarroSigüenza, A. G. (2001): Effects of global climate change on geographic distributions of Mexican Cracidae. - Ecological Modelling 144:21-30.

[49] Prasad, A. M., Iverson, L. R., Liaw, A. (2006): Newer Classification and Regression Tree Techniques: Bagging and Random Forests for Ecological Prediction. - Ecosystems, 9:181-99.

[50] R Development Core Team (2004): R: A language and environment for statistical computing. - Vienna, Austria: R Foundation for Statistical Computing.

[51] Rechinger, K. H. (1963-1998): Flora iranica. - Akademische Druck, Germany.

[52] Ridgeway, G. (1999): The state of boosting. - Computing Science and Statistics 31: 172-81.

[53] Saboohi, R., Khodagholi, M. (2013): Climatic temper of Bromus tomentellus in Isfahan province. - Applied Ecology 4:57-71.

[54] Swets, K. (1988): Measuring the accuracy of diagnostic systems. - Science 240:1285-93.

[55] Thuiller, W. (2003): BIOMOD-optimizing predictions of species distributions and projecting potential future shifts under global change. - Global Change Biology 9:1353-62.

[56] Thuiller, W. (2004): Patterns and uncertainties of species' range shifts under climate change. Global Change Biology 10:2020-7.

[57] Thuiller, W. (2007): Biodiversity: climate change and the ecologist. - Nature 448:550-2.

[58] Thuiller, W., Lavorel, S., Araújo, M. B., Sykes, M. T., Prentice, I. C. (2005): Climate change threats to plant diversity in Europe. - Proceedings of the National Academy of Sciences of the united States of America 102:8245-50.

[59] UNDP \& GEF (2005). Conservation of Biodiversity in the Central Zagros Landscape Conservation Zone. Program Report. Department of Environment, Tehran. 
[60] Vayssière, M. P., Plant, R. E., Allen-Diaz, B. H. (2000): Classification trees: an alternative non-parametric approach for predicting species distributions. - Journal of Vegetation Science 11:679-94.

[61] Venables, W. N., Ripley, B. D. (2002): Modern Applied Statistics. - Springer-Verlag, Berlin.

[62] Walther, B. A., Wisz, M. S., Rahbek, C. (2004): Known and predicted African winter distributions and habitat use of the endangered Basra reed warbler (Acrocephalus griseldis) and the near-threatened cinereous bunting (Emberiza cineracea). - Journal of Ornithology 145:287-99.

[63] Ward, D. F. (2007): Modeling the potential geographic distribution of invasive ant species in New Zealand. - Biological Invasions 9:723-35.

[64] Xu, Z. (2014): Potential distribution of invasive alien species in the upper Ili river basin: determination and mechanism of bioclimatic variables under climate change. - Environmental Earth Sciences 73(2):779-786.

[65] Zimbres, B., De Aquino, P. D., Machado, R., Silveira, L., Jácomo, A., Sollmann, R., Tôrres, N., Furtado, M., Marinho-Filho, J. (2012): Range shifts under climate change and the role of protected areas for armadillos and anteaters. - Biological Conservation 152:53-61. 